\title{
COVID-19 and United States Prison Population
}

\author{
Hina Akbar* \\ Assistant Professor of Medicine Regional One Health University of Tennessee Health Sciences Center Memphis, USA
}

\section{SHORT COMMUNICATION}

Severe acute respiratory syndrome coronavirus 2 (SARSCoV-2) also commonly known as COVID-19 pandemic is challenging and, in many cases, an overwhelming situation for the medical community as new knowledge is reported every day. As of May 15, 2020, more than 4 million confirmed cases of COVID-19, including more than 285000 deaths have been reported to WHO [1]. It is a novel infectious disease that primarily involve the respiratory tract and the lungs however can also involve multiple other organs as it progresses. Most recent data also point towards a Multisystem inflammatory syndrome in children and adolescents [1].

New data regarding variable and multitude of clinical presentations related to this novel coronavirus is emerging everyday as new cases of SARS-CoV-2 are being reported from across different regions and communities like prisons. The list of common symptoms like fever (88\% of cases), cough (68\%), vomiting (5\%) and diarrhea (3.8\%) is growing as newer data becomes available [24]. Although fever and respiratory symptoms are typical hallmarks of COVID-19 infection, other subtle acute signs, and symptoms like loss of smell and taste should not be ignored during this pandemic era. Furthermore, subtle findings of hilar lymphadenopathy on CT imaging as seen in our patient can be another clue in such patients [5-11].

Currently, most public health measures to control the spread of COVID-19 rely heavily on the identification of individuals with the highest probability of COVID-19. To identify such individuals the World Health Organization (WHO) has developed case definitions for testing [6], which rely on both the presence of classical symptoms and the epidemiological risk [3-6]. However, these definitions do not capture infected individuals with atypical presentations.

First diagnosed case of COVID-19 in United States prisons was reported from Riker's Island, the main jail complex in New York City and within few weeks over 200 cases were diagnosed despite trying to prevent further spread. Similar data was reported from across other prison facilities in United States [8]. Currently United
States facilities like jails (which house individuals awaiting trial or serving short sentences) and prisons (which house individuals who have been convicted of crimes and are serving longer sentences) are crowded places with no mechanism to segregate inmates and practice social distancing as per COVID-19 prevention guidelines.

Failing to identify all infected individuals within a confined facility increases the risk of virus transmission within the facility like prisons and detention centers and places both facility workers and other inmates and detainees at risk of infection [7]. According to an estimate, there are close to 1.5 million prisoners over the age of 55 incarcerated in US facilities and majority of them with multiple comorbidities that place them at highest risk of having a bad outcome [12]. In addition, the failure to properly diagnosis COVID-19 hinders the provision of appropriate care in facilities with already limited resources.

Thus, it is of extreme importance that subtle symptoms and clues are identified early on in confined facilities like prisons and detention centers where infection can spread rapidly in otherwise vulnerable populations if not picked quickly. The US Constitution guarantees a right to health care for people who are incarcerated but medical care availability varies greatly regarding both access and quality [13]. This is further made challenging by an increasing number of older prison population. This poses a significant public health problem considering the complexity of resources required to control spread in such facilities $[14,15]$. Citizens held in prisons and other detention facilities also need to be considered as part of the broader public health response to covid-19.

\section{REFERENCES}

1. WHO/2019-nCoV/Sci_Brief/Multisystem_Syndrome_Children/202National Health Commission of the People's Republic of China. Diagnosis and treatment protocols of pneumonia caused by a novel coronavirus.

2. Li Q, Guan X, Wu P, Wang X, Zhou L, et al. (2020) Early transmission dynamics in wuhan, china, of novel coronavirus-infected pneumonia. $\mathrm{N}$ Engl J Med 382(13): 1199-1207.
Quick Response Code:

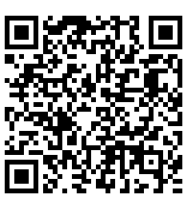

Address for correspondence: Hina Akbar, Assistant Professor of Medicine Regional One Health University of Tennessee Health Sciences Center Memphis, USA Received: May 18, 2020 Published: May 22, 2020

How to cite this article: Hina Akbar. COVID-19 and United States Prison Population. 2020 - 2(3) OAJBS.ID.000172. DOI: 10.38125/OAJBS.000172 
3. Chen N, Zhou M, Dong X (2020) Epidemiological and clinical characteristics of 99 cases of 2019 novel coronavirus pneumonia in Wuhan, China: a descriptive study. Lancet 395: 507-513.

4. Huang C, Wang Y, Li X, Ren L, Zhao J, et al. (2020) Clinical features of patients infected with 2019 novel coronavirus in Wuhan, China. Lancet 395: 497-506.

5. (2020) Global surveillance for human infection with coronavirus disease (COVID-19). WHO/2019-nCoV/Surveillance Guidance/20206.

6. Guan WJ, Ni ZY, Hu Y, Liang WH, Ou CQ et al. (2020) China medical treatment expert group for COVID-19. Clinical characteristics of coronavirus disease 2019 in China. N Engl J Med.

7. Hawks L, Woolhandler S, McCormick D (2020) COVID-19 in prisons and jails in the United States. JAMA Intern Med.

8. Kanne JP (2020) Chest CT findings in 2019 novel coronavirus (2019$\mathrm{nCoV}$ ) infections from Wuhan, China: key points for the radiologist. Radiology 29(5): 16-17.
9. Chung M, Bernheim A, Mei X, Zhang N, Huang M, et al. (2020) CT imaging features of 2019 novel coronavirus (2019-nCoV) Radiology.

10. Pan F, Ye T, Sun P, Gui S, Liang B, et al. (2020) Time course of lung changes on chest CT during recovery from 2019 novel coronavirus (COVID-19) pneumonia. Radiology.

11. Shi F, Yu Q, Huang W, Tan C (2020) 2019 Novel Coronavirus (COVID-19) Pneumonia with Hemoptysis as the Initial Symptom: CT and Clinical Features. Korean J Radiol 21(5): 537-540.

12. Akiyama MJ, Spaulding AC, Rich JD (2020) Flattening the curve for incarcerated populations - COVID-19 in jails and prisons.

13. Maruschak LM, Berzofsky M, Unangst J (2020) Medical problems of state and federal prisoners and jail inmates.

14. Andrews J (2019) The current state of public and private prison healthcare. Penn Wharton: Public Policy Initiative. 